\title{
Palliative chemotherapy beyond three courses conveys no survival or consistent quality-of-life benefits in advanced non-small-cell
} lung cancer

\section{C von Plessen ${ }^{*, 1}$, B Bergman ${ }^{2,8}$, O Andresen ${ }^{1,9}$, RM Bremnes $^{3}$, S Sundstrøm ${ }^{4}$, M Gilleryd ${ }^{2,8}$, R Stephens ${ }^{5}$, J Vilsvik ${ }^{6}, U^{A a s e b \Phi^{7}}$ and S Sörenson ${ }^{1,10}$, for the Norwegian Lung Cancer Study Group}

'Department of Thoracic Medicine, Haukeland University Hospital and Institute of Medicine, University of Bergen, N-50I8 Bergen, Norway; ${ }^{2}$ Department of Respiratory Medicine, Sahlgrenska University Hospital and Göteborg University, Gothenburg, Sweden; ${ }^{3}$ Department of Oncology, University of Tromsø and University Hospital of Northern Norway, Tromsø, Norway; ${ }^{4}$ Department of Oncology, St Olavs University Hospital, Trondheim, Norway; ${ }^{5}$ Department of Medical Oncology, Cancer Division, MRC Clinical Trials Unit, St Bartholomew's Hospital, London, UK; ${ }^{6}$ Department of Lung and Occupational Medicine, St Olavs University Hospital, Trondheim, Norway; ${ }^{7}$ Department of Medicine, University of Tromsø and University Hospital of Northern Norway, Tromsø, Norway

This randomised multicentre trial was conducted to establish the optimal duration of palliative chemotherapy in advanced non-smallcell lung cancer (NSCLC). We compared a policy of three vs six courses of new-generation platinum-based combination chemotherapy with regard to effects on quality of life (QoL) and survival. Patients with stage IIIB or IV NSCLC and WHO performance status (PS) $0-2$ were randomised to receive three (C3) or six (C6) courses of carboplatin (area under the curve (AUC) 4, Chatelut's formula, equivalent to Calvert's AUC 5) on day I and vinorelbine $25 \mathrm{mg} \mathrm{m}^{-2}$ on days I and 8 of a 3-week cycle. Key end points were QoL at 18 weeks, measured with EORTC Quality of Life Questionnaire (QLQ)-C30 and QLQ-LCI3, and overall survival. Secondary end points were progression-free survival and need of palliative radiotherapy. Two hundred and ninetyseven patients were randomised (C3 150, C6 I47). Their median age was 65 years, 30\% had PS 2 and 76\% stage IV disease. Seventyeight and 54\% of C3 and C6 patients, respectively, completed all scheduled chemotherapy courses. Compliance with QoL questionnaires was 88\%. There were no significant group differences in global QoL, pain or fatigue up to 26 weeks. The dyspnoea palliation rate was lower in the $\mathrm{C} 3$ arm at 18 and 26 weeks $(P<0.05)$, but this finding was inconsistent across different methods of analysis. Median survival in the C3 group was 28 vs 32 weeks in the C6 group $(P=0.75, \mathrm{HR} 1.04,95 \% \mathrm{Cl} 0.82-1.31)$. One- and 2year survival rates were 25 and $9 \%$ vs 25 and $5 \%$ in the $C 3$ and $C 6$ arm, respectively. Median progression-free survival was 16 and 21 weeks in the C3 and C6 groups, respectively $(P=0.21, \mathrm{HR} 0.86,95 \% \mathrm{Cl} 0.68-1.08)$. In conclusion, palliative chemotherapy with carboplatin and vinorelbine beyond three courses conveys no survival or consistent QoL benefits in advanced NSCLC. British Journal of Cancer (2006) 95, 966-973. doi:I0.1038/sj.bjc.6603383 www.bjcancer.com (c) 2006 Cancer Research UK

Keywords: chemotherapy; non-small-cell lung cancer; palliative; treatment duration; quality of life; survival

During the last decade, chemotherapy has become widely used in the palliative treatment of patients with advanced non-small-cell lung cancer (NSCLC). Today, it is acknowledged that platinumbased chemotherapy improves quality of life (QoL) (Helsing et al, 1998; Cullen et al, 1999; Gridelli et al, 1999; Thongprasert et al, 1999; Anderson et al, 2000; Ranson et al, 2000) and increases survival in patients with a good performance status (PS) by 2-3

\section{*Correspondence: Dr C von Plessen;}

E-mail: christian.von.plessen@helse-bergen.no

${ }^{8}$ For the Swedish Lung Cancer Study Group

${ }^{9}$ Current address: Fromreide Legesenter, Kjerrgarden, Norway

${ }^{10}$ Current address: Department of Pulmonary Medicine, Linköping University Hospital and University of Linköping, Linköping, Sweden Received 29 March 2006; revised 14 August 2006; accepted 14 August 2006 months (Marino et al, 1994; Anonymus, 1995; Souquet et al, 1995; Spiro et al, 2004). Two-drug platinum-based regimens have proven superior to single drug therapy and equivalent in efficacy to threedrug regimens (Alberola et al, 2003; Delbaldo et al, 2004). Given potential side effects, time spent in hospital, the cost of patient care, interindividual response variation and the palliative nature of the chemotherapy, it is clinically highly relevant to establish the optimal treatment duration. Evidence concerning this question is scarce. Two trials of induction $v s$ induction plus maintenance treatment in responding patients with advanced NSCLC suggested that treatment could be confined to two or three cycles (Buccheri et al, 1989; Weynants et al, 1997), but none of these trials specifically addressed the question of treatment duration. An expert panel at the American Society of Clinical Oncology in 1997 (Anonymus, 1997) recommended a maximum of eight chemotherapy courses in patients with stage IV NSCLC. The 2003 update of 
the guidelines recommended limiting chemotherapy to six cycles in general and stopping treatment after four cycles in stage IV patients who do not respond to treatment. These recommendations were based on a trial comparing three $v s$ six courses of mitomycin, vinblastine and cisplatin (Smith et al, 2001), and a study that compared four courses of carboplatin/paclitaxel with the same combination given until progression (Socinski et al, 2002). Neither trial showed benefits from longer treatment duration.

The current trial was designed to compare a treatment policy of three (C3) vs six (C6) cycles of a modern platinum-based two-drug combination regimen. The main research question was whether six courses would be superior to three courses with respect to QoL and survival outcomes.

\section{MATERIALS AND METHODS}

\section{Patients}

Patients with cytologically or histologically verified NSCLC stage IIIB or IV who were not candidates for treatment with a curative intent and who had a WHO PS of 0,1 or 2 were eligible. No upper age limit was defined. A white blood cell (WBC) count $>3.0 \times 10^{9} \mathrm{l}^{-1}$, platelet count $>100 \times 10^{9} \mathrm{l}^{-1}$, serum creatinine $<1.5$ times the upper reference limit, and bilirubin, ASAT and ALAT less than twice the upper reference limit were required. Exclusion criteria were other active malignancy, pregnancy or breast feeding. Patients had to be chemotherapy naïve and had to understand oral and written information.

\section{Baseline investigations}

Demographic and clinical data (age, gender, histological or cytological tumour type, PS, disease stage, body height and weight) as well as laboratory measures (haemoglobin, leucocyte and platelet counts, sodium, potassium, calcium, albumin, ASAT, ALAT, bilirubin, alkaline phosphatase, lactate dehydrogenase and creatinine) were recorded. All patients had to complete the first QoL questionnaire before randomisation.

\section{Chemotherapy}

Patients were randomised to receive three (C3) or six (C6) courses of intravenous (i.v.) carboplatin and vinorelbine. Both drugs were administered on day 1, generally on an outpatient basis, and vinorelbine was repeated on day 8 of each 3-week cycle. Haematologic parameters were measured before each chemotherapy administration and on day 15 . The dose of carboplatin was calculated by means of Chatelut's formula (area under the curve $(\mathrm{AUC})=4)$, and the vinorelbine dose was $25 \mathrm{mg} \mathrm{m}^{-2}$. Vinorelbine, diluted in $100 \mathrm{ml}$ glucose $50 \mathrm{mg} \mathrm{ml}^{-1}$, was given as a $10 \mathrm{~min}$ infusion, and carboplatin, diluted in $500 \mathrm{ml}$ glucose $50 \mathrm{mg} \mathrm{ml}^{-1}$, was infused during $1 \mathrm{~h}$. Area under the curve $=4$ in Chatelut's formula corresponds to AUC $=5$ in Calvert's. Immediately before chemotherapy on day 1 , patients received antiemetic prophylaxis with dexamethasone or betametasone $8 \mathrm{mg}$ i.v. and ondansentron $8 \mathrm{mg}$ (alternatively tropisetron $5 \mathrm{mg}$ ) i.v. Antiemetic prophylaxis on day 8 was optional.

In case of moderate haematological toxicity (WBC 2.5$2.9 \times 10^{9} 1^{-1}$ and/or platelets $75-99 \times 10^{9} 1^{-1}$ ) on day 1 of subsequent treatment courses, the doses of carboplatin and vinorelbin were reduced by $33 \%$. In case of more pronounced haematological toxicity (WBC $<2.5 \times 10^{9} 1^{-1}$ and/or platelets $<75 \times 10^{9} 1^{-1}$ ), the next chemotherapy course was postponed for 1 week and all subsequent courses remained reduced by $33 \%$. In patients with leukopenia-associated infection chemotherapy was postponed until clinical recovery and normalised WBC and platelets. At continuation, further doses were reduced by $33 \%$.
Treatment was prematurely discontinued in case of disease progression, unacceptable toxicity, or on the patient's request.

\section{Randomisation}

First patients signed the informed consent form and completed the baseline QoL questionnaire. Then they were randomised after stratification by PS $(0-1$ vs 2$)$ and by institution using a minimisation process with a probability of 0.75 (Pocock, 1985).

\section{Assessment of QoL}

Quality of life was measured by the patient-completed EORTC Core Quality of Life Questionnaire (QLQ-C30 version 2) (Aaronson et al, 1993) and the lung cancer-specific module QLQ-LC13 (Bergman et al, 1994). The QLQ-C30 measures functional aspects of QoL and symptoms commonly reported in cancer patients, while the QLQ-LC13 addresses symptoms specifically associated with lung cancer and its treatment. In the present trial, dyspnoea, pain, fatigue and global QoL were predefined as the primary QoL outcome measures. Quality of life assessments were scheduled at baseline and then at weeks 3, 6, 9 (end of C3 study treatment), 12, 15,18 (end of C6 study treatment), 26, 34, 42 and 50 in both study arms. In this study, QoL questionnaires up to 26 weeks were used for analysis. Follow-up questionnaires were either administered at the scheduled outpatient visits (Sweden) or mailed directly from the study office to the patients (Norway). Patients received one mailed reminder after 14 days if the questionnaire was not returned.

\section{Assessment of toxicity}

At the first visit in each treatment cycle and at the 8-weekly followup visits, patients underwent clinical examination with an evaluation of PS, weight and blood tests. Local investigators recorded nadir values of haemoglobin, leucocyte and platelet counts, the number of transfusions, leukopenic infections, thrombocytopenic bleedings, events of phlebitis during the study treatment period and hospital admissions due to chemotherapy side effects. After a patient's death or at registration cutoff in June 2004, investigators also reported additional treatments such as radiation, second-line chemotherapy or surgery as well as the cause of death. Mortality data were verified by the national mortality registries.

\section{Assessment of disease progression}

Tumour status was evaluated by using chest X-ray, performed in both treatment arms at baseline, after completion of the scheduled courses, and then every eighth week or at the investigators' discretion. Disease progression was defined either as an increase of the longest measurable tumour diameter by at least $20 \%$ compared to the minimum length after treatment start, or by the occurrence of new metastases, or death with residual tumour.

\section{Study end points}

Main end points of the study were QoL at 18 weeks and overall survival. Further end points were progression-free survival and need of palliative radiotherapy.

\section{Statistical considerations}

Sample size was estimated to detect a mean global QoL difference at 18 weeks of 11 score points or more on the QLQ-LC30 scale ranging from 0 to 100 , which is considered a clinically significant score difference (King, 1996; Osoba et al, 1998). With an s.d. of 23 (Aaronson et al, 1993), a type I error of $5 \%$ and power of $80 \%$ 
using a two-sided $t$-test, these criteria required 70 evaluable patients in each group. Assuming a drop-out rate by 18 weeks of about $50 \%$ due to disease progression or death, 300 randomised patients were considered necessary.

With respect to chemotherapy-related haematological side effects, the maximum toxicity ever experienced during treatment is reported. Differences between treatment arms were tested with a $\chi^{2}$ test. Survival time was measured from the date of randomisation. Survival curves were calculated by the method of Kaplan and Meier and compared by the log-rank test. Additionally, a Cox model was used for estimation of hazard ratios. All data analyses followed the intention-to-treat principle.

Quality of life outcomes were analysed in four ways: (1) group comparison of scale scores at each time point, (2) score changes from baseline, (3) AUC and (4) rates of symptom palliation defined as improvement, control or prevention, and death counted as nonpalliation (Stephens et al, 1999). Improvement was defined as a change in reported baseline symptom levels from moderate or severe (67-100 points) to none or little (0-33 points) (Langendijk et al, 2000), or from little to no symptoms without subsequent deterioration by the time of group comparison. Control of symptoms was defined as stable symptom levels between 1 and 33 points, while prevention of symptoms was assumed when patients did not report symptoms during the study period. A similar approach was used for the global QoL scale. Here, four score level ranges were defined: 0-24, $25-49,50-74$ and $75-100$, with 0 being the worst and 100 the best possible score.

Main time point for the analysis of the QoL outcome was at 18 weeks, and assessment at 26 weeks was considered important for confirmatory analyses. Assessment at 9 weeks served as quality control of treatment arm balance. Nonparametric tests were used for group comparisons. Group differences that were consistent across methods of analysis or detected with a $P$-value of 0.01 or less were interpreted as probable treatment effects.

\section{Ethical considerations}

The study protocol was approved by the Regional Ethical Committee of Western Norway and at the University of Gothenburg, Sweden.

\section{RESULTS}

\section{Patient characteristics}

From May 2000 until March 2002, 300 patients were randomised at five university hospitals and 20 regional and local hospitals in Norway (24 centres, $N=262$ ) and Sweden (one centre, $N=38$ ). Three patients with thyroid, small-cell lung and peritoneal cancer, respectively, were misdiagnosed and excluded from the study, leaving 297 patients (C3 150, C6 147). Median follow-up time by June 2004 was 36 months. Patients' pretreatment characteristics are presented in Table 1. The treatment arms were well balanced with regard to age, PS, stage and histology, while the C6 arm comprised a larger proportion of females.

\section{Compliance with chemotherapy}

Completion of all planned chemotherapy courses was reported in $117(78 \%)$ and 79 (54\%) patients in the C3 and C6 arm, respectively (Table 2). The mean and corresponding median numbers of courses were 2.7 and 3, respectively, in the C3 arm and 4.5 and 6, respectively, in the C6 arm. Vinorelbine on day 8 was omitted at least once in five patients in the C3 arm and in 20 patients in the C6 group.
Table I Patient characteristics at baseline

\begin{tabular}{|c|c|c|c|}
\hline & \multicolumn{3}{|c|}{ Treatment group } \\
\hline & C3 & C6 & Total \\
\hline No. of patients & 150 & 147 & 297 \\
\hline Sex, M/F & $104 / 46$ & $84 / 63$ & $188 / 109$ \\
\hline Age, median (range) & $64(35-84)$ & $65(34-83)$ & $64(34-84)$ \\
\hline \multicolumn{4}{|l|}{ PS } \\
\hline 0 & 31 & 26 & 57 \\
\hline 1 & 76 & 74 & 150 \\
\hline 2 & 43 & 47 & 90 \\
\hline \multicolumn{4}{|l|}{ Stage } \\
\hline$\| \mathrm{B}$ & 37 & 34 & 71 \\
\hline IV & 113 & 113 & 226 \\
\hline \multicolumn{4}{|l|}{ Histology } \\
\hline Adenocarcinoma & 63 & 66 & 129 \\
\hline Squamous cell & 46 & 33 & 79 \\
\hline Large cell & 15 & 21 & 36 \\
\hline Adenosquamous & 3 & 0 & 3 \\
\hline NSCLC - not specified & 23 & 27 & 50 \\
\hline
\end{tabular}

NSCLC $=$ non-small-cell lung cancer; $\mathrm{PS}=$ performance status.

Table 2 Numbers and percentages of patients treated at each course

\begin{tabular}{lcrcccc}
\hline & \multicolumn{7}{c}{ Course number } \\
\cline { 2 - 7 } & $\mathbf{1}$ & $\mathbf{2}$ & $\mathbf{3}$ & $\mathbf{4}$ & $\mathbf{5}$ & $\mathbf{6}$ \\
\hline C3 $(N=150)$ & 150 & 136 & 117 & - & - & - \\
Per cent & 100 & 91 & 78 & - & - & - \\
C6 $(N=147)$ & 143 & 134 & 116 & 99 & 88 & 79 \\
Per cent & 97 & 91 & 79 & 67 & 60 & 54 \\
\hline
\end{tabular}

C3 patients were randomised to receive three courses, while C6 patients were randomised to receive six courses of chemotherapy

\section{Compliance with QoL questionnaires}

Two hundred and ninety-seven patients returned 1715 completed questionnaires (of 1911 expected, deceased patients excluded) during the initial 26 weeks study period. Thirty questionnaires were not adequately filled in, leaving 1685 evaluable questionnaires (C3, $N=826 ; \mathrm{C} 6, N=859$ ). Thus, the compliance rate with QoL questionnaires during the study period was $88 \%$ (C3 $86 \%$; C6 $91 \%)$.

\section{QoL outcome}

Scores for global QoL as well as dyspnoea, pain and fatigue at baseline, 9, 18 and 26 weeks are displayed in Table 3.

C6 patients reported lower dyspnoea scores, as measured by the three-item QLQ-LC13 dyspnoea scale, at 18 and 26 weeks than did the C3 patients. These group differences were not seen with the single-item QLQ-C30 dyspnoea measure. No significant group differences were seen at any time point for pain, fatigue or global QoL.

Mean score changes from baseline to 9, 18 and 26 weeks are shown in Figure 1.

The changes of dyspnoea scores suggested a small symptom increase over time in both treatment groups, with no significant group differences at 18 or 26 weeks. Changes of pain scores did not differ up to 18 weeks, whereas a trend towards a less favourable outcome in the C6 group at 26 weeks was detected $(P=0.08)$. 
Table 3 Mean scores for the primary QoL outcome dimensions at 0, 9, 18 and 26 weeks by treatment group

\begin{tabular}{|c|c|c|c|c|c|c|c|c|}
\hline & \multicolumn{2}{|c|}{0 weeks } & \multicolumn{2}{|c|}{9 weeks } & \multicolumn{2}{|c|}{18 weeks } & \multicolumn{2}{|c|}{26 weeks } \\
\hline No. of questionnaires & 148 & 147 & 105 & 108 & 78 & 87 & 63 & 73 \\
\hline Global QoL & 50.8 & 56.7 & 54.1 & 58.4 & 49.6 & 55.3 & 49.0 & 52.4 \\
\hline Dyspnoea (QLQ-C30) & 49.0 & 48.3 & 46.1 & 41.7 & 53.0 & 47.7 & 54.5 & 46.6 \\
\hline Dyspnoea (QLQ-LCI3) & 37.9 & 37.8 & 38.6 & 35.0 & 45.1 & $37.6^{*}$ & 47.9 & $38.3^{*}$ \\
\hline
\end{tabular}

$\mathrm{QLQ}=\mathrm{Quality}$ of Life Questionnaire; QoL = quality of life. All scale scores range from 0 to 100. For Global QoL, a higher score indicates better QoL, while for the symptom measures, a higher score indicates more pronounced symptoms. ${ }^{*} P<0.05$; Mann-Whitney $U$-test.
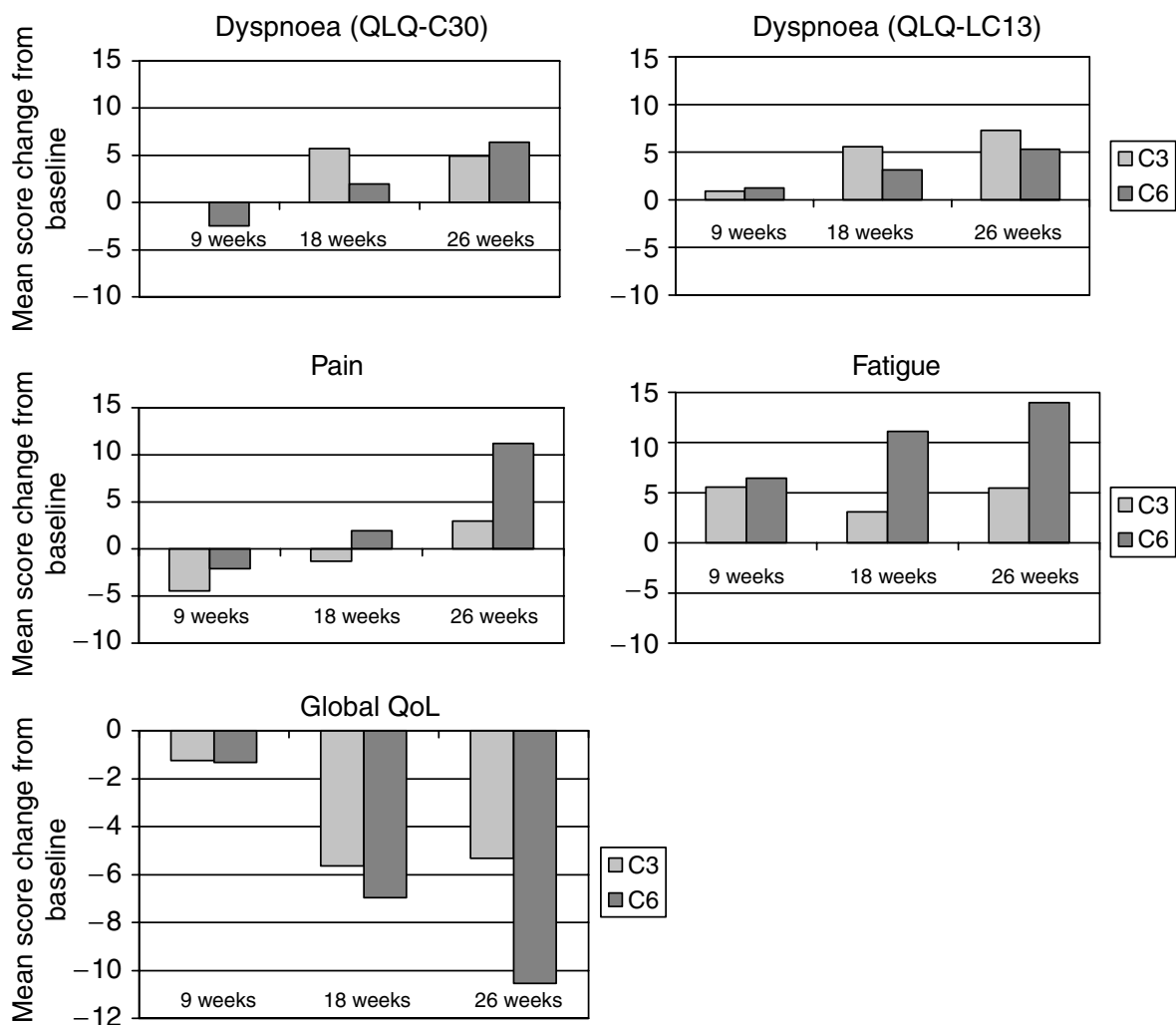

Figure I Mean score changes from baseline to key follow-up time points for primary outcome symptoms and global QoL, calculated from individual patients measured at baseline and 9 weeks $(C 3, N=105 ; C 6, N=103)$, I8 weeks $(C 3, N=77 ; C 6, N=87)$ and 26 weeks $(C 3, N=62 ; C 6, N=73)$, respectively. For symptom measures score, changes $>0$ indicate increased symptoms (i.e. deterioration), while for the global QoL score, changes $>0$ indicate improvement. No significant group differences were seen.

Similarly, fatigue scores tended to increase somewhat more in the C6 group at $18(P=0.13)$ and 26 weeks $(P=0.09)$. Global QoL tended to deteriorate over time in both $\mathrm{C} 3$ and $\mathrm{C} 6$ patients. However, score changes did not differ significantly between the groups.

Analysis of AUC up to 18 and 26 weeks did not reveal any significant group differences in any of the core symptom items or global QoL (data not shown).

Finally, palliation rates of the core symptoms and global QoL are displayed in Figure 2.

Palliation rates varied from $34 \%$ (fatigue) to $55 \%$ (global QoL) by 9 weeks (C3 and $\mathrm{C} 6$ combined), but declined over time. A significantly larger proportion of C6 than C3 patients were still palliated with regard to dyspnoea at $18 \quad(P<0.05)$ and 26
$(P<0.001)$ weeks when measured by the three-item QLQ-LC13 dyspnoea scale, but this group difference could not be detected with the single-item QLQ-C30 dyspnoea measure. As for the fatigue measure, there seemed to be a palliation advantage for the C6 group at 9 weeks $(P<0.05)$, which could hardly be attributable to treatment effects. By the 18 and 26 weeks follow-up measurements, there were no significant group differences in palliation of fatigue, pain or global QoL.

With regard to the remaining QoL measures, which were used for exploratory purposes, there was a larger deterioration in role functioning scores from baseline to 26 weeks in the C6 group (mean score change $-19.0 v s-7.4$ in the $\mathrm{C} 3$ group, $P<0.05$ ) and increased nausea and vomiting by 18 weeks (mean score change $+4.2 v s-0.4$ in the $\mathrm{C} 3$ group, $P<0.05)$. In the $\mathrm{C} 3$ group, there was 

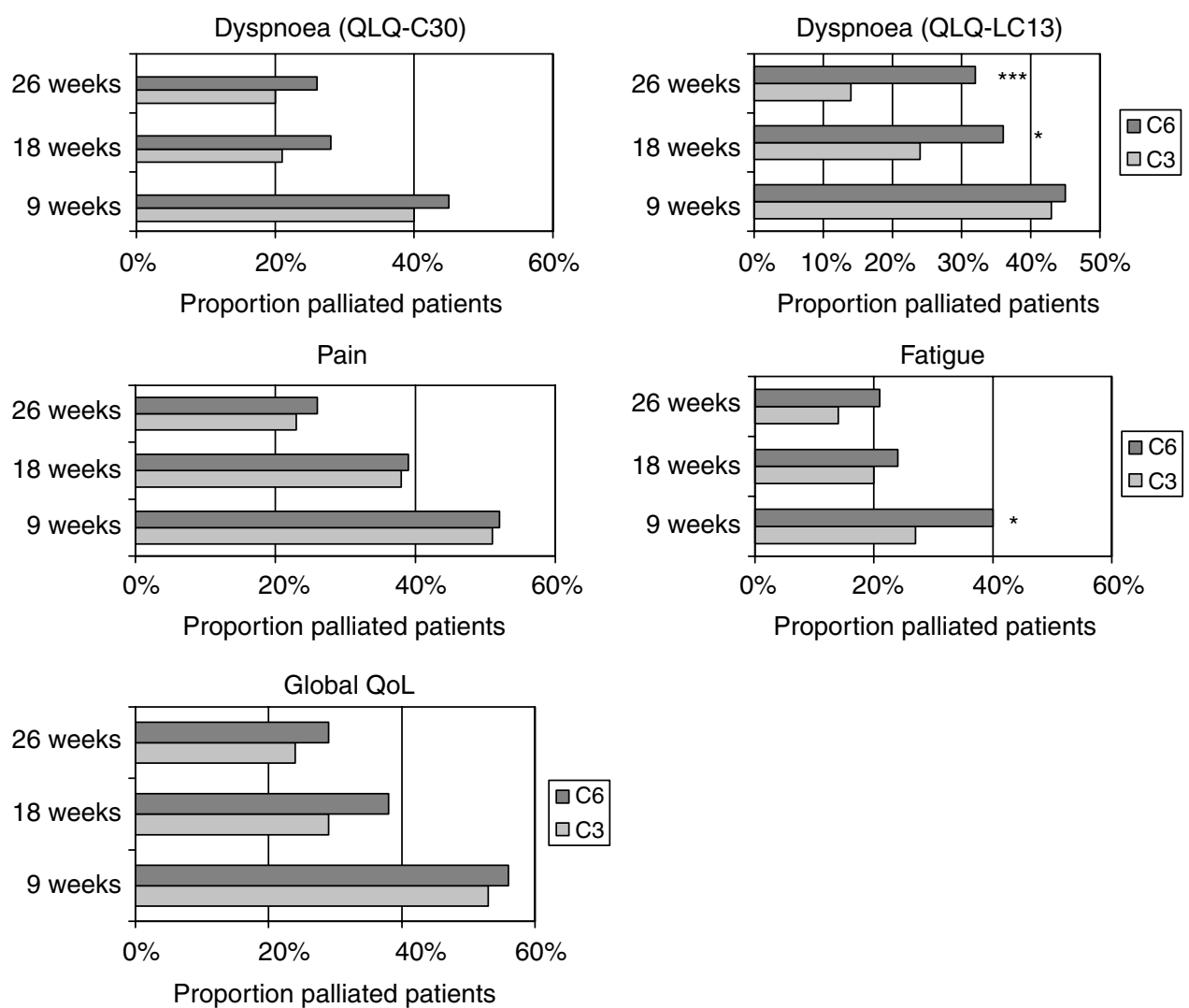

Figure 2 Rates of palliation of core symptoms and global QoL, defined as improvement, control or prevention, and death counted as nonpalliation. Numbers of evaluable patients (including deceased) were 256 at 9 weeks (C3 127, C6 I29), 270 at I 8 weeks (C3 I33, C6 I37) and 282 at 26 weeks (C3 | 40, C6 | 42). *P $<0.05$; **** $P<0.001$; $\chi^{2}$ test.

a larger improvement in the arm/shoulder pain score by 18 weeks (mean score change -10 vs -0.8 in the C6 group, $P<0.05$ ). Otherwise, there were no significant group differences in score levels, score changes, AUC or palliation rates up to 26 weeks.

\section{Survival}

Overall survival is shown in Figure 3. Median survival time was 28 and 32 weeks in the $\mathrm{C} 3$ and $\mathrm{C} 6$ arm, respectively $(P=0.75)$. The hazard ratio for the $\mathrm{C} 6 \mathrm{arm}$ was 1.04 (95\% CI $0.82-1.31)$. One- and 2 -year survival rates were 25 and $9 \%$ vs 25 and 5\% in the C3 and C6 arm, respectively.

By June 2004, 288 patients were dead. The cause of death was recorded in 275 patients, 254 deaths were related to lung cancer, two to chemotherapy side effects and three were related to side effects of other cancer treatments. Sixteen patients died of other causes than lung cancer or its treatment.

Progression-free survival time is shown in Figure 4. Median progression-free survival time was 16 and 21 weeks in the $\mathrm{C} 3$ and C6 groups, respectively $(P=0.21)$. The hazard ratio for the $\mathrm{C} 6 \mathrm{arm}$ was $0.86(95 \%$ CI $0.68-1.08)$.

\section{Additional treatment after completed chemotherapy}

A total of 285 patients were assessable for additional treatments after completed first-line chemotherapy. Of these patients, 62 $(22 \%)$ in the $\mathrm{C} 3$ arm and $68(24 \%)$ in the $\mathrm{C} 6$ arm received palliative irradiation $(P=0.4)$. Overall, sixty-four patients received secondline chemotherapy, $35(12 \%)$ in the C3 group and $29(10 \%)$ the C6 group $(P=0.4)$.



Figure 3 Overall survival by treatment group: C3 (randomised to receive three courses) marked with solid line and C6 (randomised to receive six courses) with dotted line. $P$-value refers to a log-rank test.

\section{Toxicity}

Haematological toxicities are presented in Table 4. Approximately one-third of patients in both treatment groups experienced grade 3 or 4 leukopenia. 


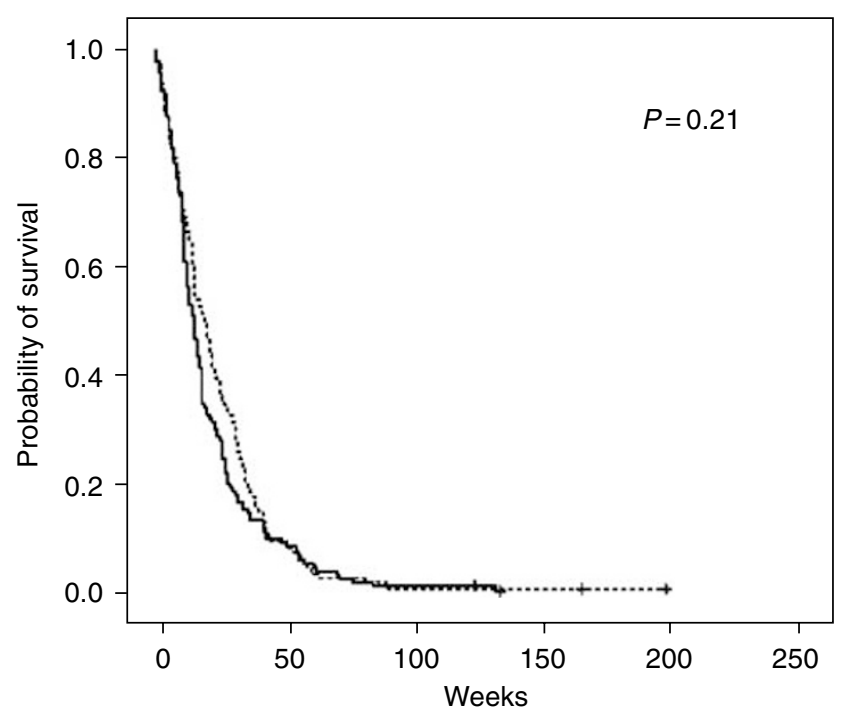

Figure 4 Progression-free survival by treatment group: C3 (randomised to receive three courses) marked with solid line and C6 (randomised to receive six courses) with dotted line. P-value refers to a log-rank test.

Table 4 Numbers (\%) of patients in each treatment arm experiencing haematological toxicity by worst CTC grading

\begin{tabular}{|c|c|c|c|c|c|}
\hline \multirow[b]{2}{*}{ CTC grade } & \multicolumn{2}{|c|}{ C3 $(N=150)$} & \multicolumn{2}{|c|}{ C6 $(N=147)$} & \multirow[b]{2}{*}{$P$-value } \\
\hline & $1+2$ & $3+4$ & $1+2$ & $3+4$ & \\
\hline WBC & $54(36)$ & $52(35)$ & $57(40)$ & $46(32)$ & 0.79 \\
\hline Haemoglobin & 133 (89) & $5(3)$ & $121(85)$ & $13(9)$ & 0.11 \\
\hline Platelets & $30(20)$ & $2(1)$ & $50(35)$ & I (I) & 0.02 \\
\hline
\end{tabular}

$\mathrm{CTC}=$ common toxicity criteria; $\mathrm{WBC}=$ white blood cell. $P$-values refer to $\chi^{2}$ tests.

Other side effects were evaluable in $87 \%$ of all patients. In the $\mathrm{C} 3$ group, $27(20 \%)$ patients had leukopenic infections compared with $21(16 \%)$ in the C6 group $(P=0.5)$. The total number of blood transfusions was $20(15 \%)$ in the C3 vs $44(34 \%)$ in the C6 group $(P=0.003)$. No thrombocytopenic bleedings were recorded. There was one episode of grade 5 toxicity in each treatment arm. Fourteen (11\%) vs $18(14 \%)$ in the C3 and C6 group, respectively, had episodes of phlebitis $(P=0.5)$. Thirty-two (C3) and 26 (C6) hospital admissions due to chemotherapy side effects were recorded $(P=0.3)$.

\section{DISCUSSION}

In this randomised multicentre trial in two Scandinavian countries a treatment policy of six courses of a platinum-based two-drug chemotherapy regimen did not convey any survival or consistent QoL benefits over three courses of the same regimen, with comparable toxicity. These findings challenge recent guidelines that recommend a maximum of six courses of chemotherapy in stage IV NSCLC (Pfister et al, 2004).

In this study, group differences in QoL measures were generally small and inconsistent across methods of analysis. The QoL results did not indicate improved pain or fatigue control with the C6 regimen. Neither did patients' functioning or global QoL significantly improve with the longer treatment. On the other hand, the perceived side effects of prolonged treatment were marginal, mainly consisting of moderately increased nausea and vomiting. The only variable that pointed to a potential benefit from prolonged treatment was improved dyspnoea control at 18 and 26 weeks in the C6 vs C3 arm when measured by the three-item QLQLC13 scale. However, no corresponding difference in dyspnoea control was shown in score changes from baseline or AUC comparison, neither was it reproduced with the single-item QLQC30 dyspnoea measure. The latter could possibly be explained by an increased sensitivity to clinical change with the three-item scale (Bergman et al, 1994).

The study is representative of the everyday clinical setting with over $20 \%$ of all newly diagnosed stage IIIB and IV NSCLC patients in the Norwegian study regions (Cancer Registry of Norway, 2005) participating. Of these patients, $45 \%$ were over the age of 65 years compared to $61 \%$ in the Norwegian Cancer Registry. Still, the proportion of elderly patients was higher than in typical clinical lung cancer trials (Hutchins et al, 1999; Lewis et al, 2003; Murthy et al, 2004).

At the time this study was planned, single-drug efficacy of vinorelbine had been demonstrated (Gridelli et al, 1997) and the combination of carboplatin and vinorelbine was well tolerated in phase II trials (Masotti et al, 1995; Pronzato et al, 1996; Gridelli et al, 1998, 1999; Santomaggio et al, 1998). Later vinorelbine/ cisplatin regimens have shown similar efficacy when compared to other cisplatin combinations with third-generation cytotoxic drugs (Schiller et al, 2002). A recent meta-analysis comparing cisplatin and carboplatin in the treatment of advanced NSCLC found no significant differences in overall survival in spite of a higher response rate for cisplatin. Treatment with cisplatin was associated with more nausea-vomiting than carboplatin (Ardizzoni et al, 2006). For the palliative treatment in the unselected population of this study, we assumed equal efficacy of both drugs and chose carboplatin because of its more feasible outpatient administration and more favourable toxicity profile.

The proportion of patients receiving second-line chemotherapy (C3 $12 \%$, C6 10\%) was small in comparison to a recent survey (Hensing et al, 2005) that reported $45 \%$ second-line chemotherapy for the patient population of an earlier phase III trial (Socinski et al, 2002). However, these figures are representative of the pattern of chemotherapy use for NSCLC in Norway when the study was initiated in 2000. In fact, the study was instrumental in introducing chemotherapy for advanced NSCLC in the country. A consequence of the relatively infrequent use of second-line treatment is that the analysis of overall survival by first-line treatment strategies is less biased.

The evaluation of progression-free survival and chemotherapy toxicity reported by the local investigators was not systematically reviewed and the information on validity of these data is limited. However, the main study end points, overall survival and QoL, were recorded independently of local investigators, and were therefore not affected by this limitation.

During the inclusion phase of the present study, a British group (Smith et al, 2001) reported the results from a randomised trial of three $v s$ six courses of mitomycin, vinblastine and cisplatin in 308 patients with NSCLC, stage IIIB and IV, and PS $0-2$. They found similar median survival times and 1-year survival rates for patients in both study arms, indicating no survival benefit from the longer duration of chemotherapy. Furthermore, QoL and duration of symptom relief were similar in both arms, although patients receiving six courses reported somewhat more pronounced fatigue, nausea and vomiting, probably related to increased treatment toxicity. The two studies were comparable in terms of design and study population, but ours had a higher median age of 65 vs 63 years in the British study. Furthermore, treatment compliance was higher in this study, with 78 and $54 \%$ completion rate in the $\mathrm{C} 3$ and C6 arm, respectively, compared with 72 and $31 \%$ in the British trial. This difference probably reflects a better tolerance for the vinorelbine/carboplatin regimen.

In 2002, Socinski et al (2002) reported the results from a randomised study comparing four courses of carboplatin/ 
paclitaxel chemotherapy with continuous treatment until progression in 230 patients with NSCLC stage IIIB or IV and PS $0-1$. In both arms, the median number of actually delivered chemotherapy courses was 4 , with $57 \%$ of patients in the short treatment arm receiving all scheduled treatments, and $42 \%$ of patients in the continuous treatment arm receiving five or more courses. In spite of their generally more fit study population (no PS 2 patients), prolonged treatment did not yield any benefits in terms of survival, QoL or response rates. An increasing rate of peripheral neuropathy was seen in patients receiving more than four courses.

Limiting the number of chemotherapy courses would reduce total treatment costs (Braud et al, 2003) as cytotoxic drugs and their administration constitute 14-20\% (Jaakkimainen et al, 1990; Billingham et al, 2002) of the health-care costs of advanced lung cancer. Furthermore, as many patients spend hours in hospital (Plessen von and Aslaksen, 2005) and travelling back and forth for chemotherapy, a reduction in the number of courses will also directly benefit the patient. Finally, reducing the number of courses can free limited oncological outpatient capacity (Clegg et al, 2001).

Around $50 \%$ of patients with lung cancer receive chemotherapy during more than 2 months of the final 6 months of their lives, and $10 \%$ during their last 4 weeks (Emanuel et al, 2003). These proportions are considerable taking into account limited benefits (Spiro and Porter, 2002) and toxicity of chemotherapy. Furthermore, it cannot be expected that patients, after completed treatment, generally have a positive attitude towards chemotherapy (Silvestri et al, 1998). On the other hand, it has been shown that patients with cancer are willing to accept toxic therapy for minimal benefits (Slevin et al, 1990; Bremnes et al, 1995; Hirose et $a l, 2005)$. It is a challenge for any clinician to give balanced information about potential effects and side effects of palliative chemotherapy and when to stop the treatment (Mitchell and Currow, 2002). The confirmatory evidence from this study, indicating similar QoL and survival after three or six courses of chemotherapy, will hopefully support clinicians and their patients in the decision-making process regarding the duration of palliative chemotherapy, and should be taken into account in clinical guidelines on the palliative treatment of advanced NSCLC.

\section{ACKNOWLEDGEMENTS}

The study was supported by grants from the Norwegian Cancer Society and Pierre Fabre Médicament. We thank Tore Wentzel Larsen, Centre for Clinical Research, Haukeland University Hospital for statistical advice, Randi Eikeland, Clinical Cancer Research Office, Haukeland University Hospital, Bergen, Norway for excellent data management and Odd Mørkve, Department of Thoracic Medicine Haukeland University Hospital for advice on the paper.

Investigators at study centres:

FJ Halvorsen, Førde Central Hospital, Førde; Ø Furnes, Hammerfest Hospital, Hammerfest; S Fluge, PS Munk and K Skaug, Haugesund Hospital, Haugesund; AH Andreassen, Ø Fløtten, A Hermes, S Noshie, O Overå, K Stang Volden and T Vigander, Haukeland University Hospital, Bergen; M Ongkiehong and C Reisse, Helgeland Hospital, Mo i Rana; R Berntsen and C Notelid, Helgeland Hospital, Mosjøen; HH Strøm, Helgeland Hospital, Sandnessjøen; T Engjom, S Hjørleifsson, E Lange and H Skuterud, Hålogaland Hospital, Harstad; A Boeckmann and JS Svendsen, Hålogaland Hospital, Narvik; K Weyde, Innlandet Hospital Trust, Gjøvik; K Fjæstad and K Watne, Innlandet Hospital Trust, Hamar; OC Haanæs, Innlandet Hospital Trust, Tynset; T Fjose and M Mæhönen, Kirkenes Hospital, Kirkenes; O Herlofsen, Kristiansund Hospital, Kristiansund; AM Heggli, R Kibsgaard and T Naustdal, Levanger Hospital, Levanger; B Jakobsen, Molde Hospital, Molde; RS Brantzæg, Namsos Hospital, Namsos; O Alexandersen, E Heitmann and MS Jordhøy, Nordland Hospital, Bodø; G Liljedal, Nordland Hospital Lofoten, Gravdal; T Brezicka, H Fjällbrant, M Nicklasson and I Soukka, Sahlgrenska University Hospital, Göteborg; L Bjermer, M Dalen, Ø Grimstad, I Harstad, BO Haugen, AH Henriksen, H Hjelde, M Johansen, D Kulosman, RT Lund, M Mathisen, G Qvigstad, A Raknerud, P Rebhan, O Røe, S Sørhaug, H Tøndel, R Walstad and AE Østvik, St Olavs Hospital, Trondheim; $\emptyset$ Fløtterød, G Hopen, T Jensen and Telemark Public Hospital, Skien; S Haraldsdottir and F Stornes, Ullevål University Hospital, Oslo; R Byrkjeland, M Johansen, S Nissen, A Reigstad, N Ritland, P Røyset, T Steigen and B Wembstad, University Hospital of North Norway, Troms $\varnothing$; CB Alm, Voss Hospital, Voss; K Larsen, K Roth, F Wammer and H Aarsnes, Allesund Hospital, Alesund.

\section{REFERENCES}

Aaronson NK, Ahmedzai S, Bergman B, Bullinger M, Cull A, Duez NJ, Filiberti A, Flechtner H, Fleishman SB, de Haes JC (1993) The European Organization for Research and Treatment of Cancer QLQ-C30: a qualityof-life instrument for use in international clinical trials in oncology. J Natl Cancer Inst 85: 365-376

Alberola V, Camps C, Provencio M, Isla D, Rosell R, Vadell C, Bover I, Ruiz-Casado A, Azagra P, Jimenez U, Gonzalez-Larriba JL, Diz P, Cardenal F, Artal A, Carrato A, Morales S, Sanchez JJ, de las Penac R, Felip E, Lopez-Vivanco G (2003) Cisplatin plus gemcitabine versus a cisplatin-based triplet versus nonplatinum sequential doublets in advanced non-small-cell lung cancer: a Spanish Lung Cancer Group phase III randomized trial. J Clin Oncol 21: 3207-3213

Anderson H, Hopwood P, Stephens RJ, Thatcher N, Cottier B, Nicholson M, Milroy R, Maughan TS, Falk SJ, Bond MG, Burt PA, Connolly CK, McIllmurray MB, Carmichael J (2000) Gemcitabine plus best supportive care (BSC) vs BSC in inoperable non-small cell lung cancer - a randomized trial with quality of life as the primary outcome. UK NSCLC Gemcitabine Group. Non-Small Cell Lung Cancer. Br J Cancer 83: 447-453

Anonymous (1995) Chemotherapy in non-small cell lung cancer: a metaanalysis using updated data on individual patients from 52 randomised clinical trials. Non-small Cell Lung Cancer Collaborative Group. BMJ 311: 899-909

Anonymous (1997) Clinical practice guidelines for the treatment of unresectable non-small-cell lung cancer. Adopted on May 16, 1997 by the American Society of Clinical Oncology. J Clin Oncol 15: 2996-3018
Ardizzoni AM, Tiseo L, Boni R, Rosell FV, Fossella JH, Schiller M, Paesmans D, Radosavljevic A, Paccagnella P, Mazzanti D, Bisset D (2006) CISCA (cisplatin $v s$ carboplatin) meta-analysis: an individual patient data meta-analysis comparing cisplatin versus carboplatin-based chemotherapy in first-line treatment of advanced non-small cell lung cancer (NSCLC). J Clin Oncol 24(18S): 7011

Bergman B, Aaronson NK, Ahmedzai S, Kaasa S, Sullivan M (1994) The EORTC QLQ-LC13: a modular supplement to the EORTC Core Quality of Life Questionnaire (QLQ-C30) for use in lung cancer clinical trials. EORTC Study Group on Quality of Life. Eur J Cancer 30A: 635-642

Billingham LJ, Bathers S, Burton A, Bryan S, Cullen MH (2002) Patterns, costs and cost-effectiveness of care in a trial of chemotherapy for advanced non-small cell lung cancer. Lung Cancer 37: 219-225

Braud AC, Levy-Piedbois C, Piedbois P, Piedbois Y, Livartovski A, Le VB, Tredaniel J, Reboul F, Brewer Y, Talbi S, Blanchon F, Paschen B, Durand-Zaleski I (2003) Direct treatment costs for patients with lung cancer from first recurrence to death in France. Pharmacoeconomics 21: $671-679$

Bremnes RM, Andersen K, Wist EA (1995) Cancer patients, doctors and nurses vary in their willingness to undertake cancer chemotherapy. Eur J Cancer 31A: 1955 - 1959

Buccheri GF, Ferrigno D, Curcio A, Vola F, Rosso A (1989) Continuation of chemotherapy versus supportive care alone in patients with inoperable non-small cell lung cancer and stable disease after two or three cycles of MACC. Results of a randomized prospective study. Cancer 63: 428-432 
Cancer Registry of Norway (2005) Cancer in Norway 2003, www. kreftregisteret.no/frame.htm?english.htm

Clegg A, Scott DA, Sidhu M, Hewitson P, Waugh N (2001) A rapid and systematic review of the clinical effectiveness and cost-effectiveness of paclitaxel, docetaxel, gemcitabine and vinorelbine in non-small-cell lung cancer. Health Technol Assess 5: 1-195

Cullen MH, Billingham LJ, Woodroffe CM, Chetiyawardana AD, Gower NH, Joshi R, Ferry DR, Rudd RM, Spiro SG, Cook JE, Trask C, Bessell E, Connolly CK, Tobias J, Souhami RL (1999) Mitomycin, ifosfamide, and cisplatin in unresectable non-small-cell lung cancer: effects on survival and quality of life. J Clin Oncol 17: 3188-3194

Delbaldo C, Michiels S, Syz N, Soria JC, Le CT, Pignon JP (2004) Benefits of adding a drug to a single-agent or a 2-agent chemotherapy regimen in advanced non-small-cell lung cancer: a meta-analysis. JAMA 292: 470 - 484

Emanuel EJ, Young-Xu Y, Levinsky NG, Gazelle G, Saynina O, Ash AS (2003) Chemotherapy use among Medicare beneficiaries at the end of life. Ann Intern Med 138: 639-643

Gridelli C, Perrone F, Gallo C (1999) Effects of vinorelbine on quality of life and survival of elderly patients with advanced non-small-cell lung cancer. The Elderly Lung Cancer Vinorelbine Italian Study Group. J Natl Cancer Inst 91: 66-72

Gridelli C, Perrone F, Gallo C, De MF, Ianniello G, Cigolari S, Cariello S, Di CF, D’Aprile M, Rossi A, Migliorino R, Bartolucci R, Bianco AR, Pergola M, Monfardini S (1997) Vinorelbine is well tolerated and active in the treatment of elderly patients with advanced non-small cell lung cancer. A two-stage phase II study. Eur I Cancer 33: 392 - 397

Gridelli C, Perrone F, Ianniello GP, Brancaccio L, Iaffaioli RV, Curcio C, D’Aprile M, Cioffi R, Cigolari S, Rossi A, Palazzolo G, Veltri E, Pergola M, De PS, Gallo C, Monfardini S, Bianco AR (1998) Carboplatin plus vinorelbine, a new well-tolerated and active regimen for the treatment of extensive-stage small-cell lung cancer: a phase II study. Gruppo Oncologico Centro-Sud-Isole. J Clin Oncol 16: 1414-1419

Helsing M, Bergman B, Thaning L, Hero U (1998) Quality of life and survival in patients with advanced non-small cell lung cancer receiving supportive care plus chemotherapy with carboplatin and etoposide or supportive care only. A multicentre randomised phase III trial. Joint Lung Cancer Study Group. Eur J Cancer 34: 1036 - 1044

Hensing TA, Schell MJ, Lee JH, Socinski MA (2005) Factors associated with the likelihood of receiving second line therapy for advanced non-small cell lung cancer. Lung Cancer 47: 253-259

Hirose T, Horichi N, Ohmori T, Kusumoto S, Sugiyama T, Shirai T, Ozawa T, Ohnishi T, Adachi M (2005) Patients preferences in chemotherapy for advanced non-small-cell lung cancer. Intern Med 44: 107-113

Hutchins LF, Unger JM, Crowley JJ, Coltman Jr CA, Albain KS (1999) Underrepresentation of patients 65 years of age or older in cancertreatment trials. N Engl J Med 341: 2061 - 2067

Jaakkimainen L, Goodwin PJ, Pater J, Warde P, Murray N, Rapp E (1990) Counting the costs of chemotherapy in a National Cancer Institute of Canada randomized trial in nonsmall-cell lung cancer. J Clin Oncol 8: $1301-1309$

King MT (1996) The interpretation of scores from the EORTC quality of life questionnaire QLQ-C30. Qual Life Res 5: 555-567

Langendijk JA, ten Velde GP, Aaronson NK, de Jong JM, Muller MJ, Wouters EF (2000) Quality of life after palliative radiotherapy in nonsmall cell lung cancer: a prospective study. Int J Radiat Oncol Biol Phys 47: $149-155$

Lewis JH, Kilgore ML, Goldman DP, Trimble EL, Kaplan R, Montello MJ, Housman MG, Escarce JJ (2003) Participation of patients 65 years of age or older in cancer clinical trials. J Clin Oncol 21: 1383-1389

Marino P, Pampallona S, Preatoni A, Cantoni A, Invernizzi F (1994) Chemotherapy $v s$ supportive care in advanced non-small-cell lung cancer. Results of a meta-analysis of the literature. Chest 106: 861-865

Masotti A, Borzellino G, Zannini G, Laterza E, Ricci F, Morandini G (1995) Efficacy and toxicity of vinorelbine-carboplatin combination in the treatment of advanced adenocarcinoma or large-cell carcinoma of the lung. Tumori 81: $112-116$

Mitchell G, Currow D (2002) Chemotherapy and radiotherapy. When to call it quits. Aust Fam Physician 31: 129-133
Murthy VH, Krumholz HM, Gross CP (2004) Participation in cancer clinical trials: race-, sex-, and age-based disparities. JAMA 291: 2720 2726

Osoba D, Rodrigues G, Myles J, Zee B, Pater J (1998) Interpreting the significance of changes in health-related quality-of-life scores. J Clin Oncol 16: $139-144$

Pfister DG, Johnson DH, Azzoli CG, Sause W, Smith TJ, Baker Jr S, Olak J, Stover D, Strawn JR, Turrisi AT, Somerfield MR (2004) American Society of Clinical Oncology treatment of unresectable non-small-cell lung cancer guideline: update 2003. J Clin Oncol 22: 330-353

Plessen von C, Aslaksen A (2005) Improving the quality of palliative care for ambulatory patients with lung cancer. BMJ 330: 1309-1313

Pocock SJ (1985) Current issues in the design and interpretation of clinical trials. BMJ (Clin Res Ed) 290: 39-42

Pronzato P, Ghio E, Losardo PL, Landucci M, Vaira F, Vigani A (1996) Carboplatin and vinorelbine in advanced non-small-cell lung cancer. Cancer Chemother Pharmacol 37: 610-612

Ranson M, Davidson N, Nicolson M, Falk S, Carmichael J, Lopez P, Anderson H, Gustafson N, Jeynes A, Gallant G, Washington T, Thatcher N (2000) Randomized trial of paclitaxel plus supportive care versus supportive care for patients with advanced non-small-cell lung cancer. J Natl Cancer Inst 92: 1074-1080

Santomaggio C, Tucci E, Rinaldini M, Algeri R, Righi R, Pepi F, Ghezzi P, Andrei A, Bellezza A (1998) Carboplatin and vinorelbine in the treatment of advanced non-small-cell lung cancer: a multicenter phase II study. Am J Clin Oncol 21: 67-71

Schiller JH, Harrington D, Belani CP, Langer C, Sandler A, Krook J, Zhu J, Johnson DH (2002) Comparison of four chemotherapy regimens for advanced non-small-cell lung cancer. $N$ Engl J Med 346: $92-98$

Silvestri G, Pritchard R, Welch HG (1998) Preferences for chemotherapy in patients with advanced non-small cell lung cancer: descriptive study based on scripted interviews. BMJ 317: 771-775

Slevin ML, Stubbs L, Plant HJ, Wilson P, Gregory WM, Armes PJ, Downer SM (1990) Attitudes to chemotherapy: comparing views of patients with cancer with those of doctors, nurses, and general public. BMJ 300: 1458 1460

Smith IE, O'Brien ME, Talbot DC, Nicolson MC, Mansi JL, Hickish TF, Norton A, Ashley S (2001) Duration of chemotherapy in advanced nonsmall-cell lung cancer: a randomized trial of three versus six courses of mitomycin, vinblastine, and cisplatin. J Clin Oncol 19: 1336-1343

Socinski MA, Schell MJ, Peterman A, Bakri K, Yates S, Gitten R, Unger P, Lee J, Lee JH, Tynan M, Moore M, Kies MS (2002) Phase III trial comparing a defined duration of therapy versus continuous therapy followed by second-line therapy in advanced-stage IIIB/IV non-small-cell lung cancer. J Clin Oncol 20: 1335-1343

Souquet PJ, Chauvin F, Boissel JP, Bernard JP (1995) Meta-analysis of randomised trials of systemic chemotherapy versus supportive treatment in non-resectable non-small cell lung cancer. Lung Cancer 12(Suppl 1): S147-S154

Spiro SG, Porter JC (2002) Lung cancer - where are we today? Current advances in staging and nonsurgical treatment. Am J Respir Crit Care Med 166: $1166-1196$

Spiro SG, Rudd RM, Souhami RL, Brown J, Fairlamb DJ, Gower NH, Maslove L, Milroy R, Napp V, Parmar MK, Peake MD, Stephens RJ, Thorpe H, Waller DA, West P (2004) Chemotherapy versus supportive care in advanced non-small cell lung cancer: improved survival without detriment to quality of life. Thorax 59: $828-836$

Stephens RJ, Hopwood P, Girling DJ (1999) Defining and analysing symptom palliation in cancer clinical trials: a deceptively difficult exercise. Br J Cancer 79: 538 - 544

Thongprasert S, Sanguanmitra P, Juthapan W, Clinch J (1999) Relationship between quality of life and clinical outcomes in advanced non-small cell lung cancer: best supportive care (BSC) versus BSC plus chemotherapy. Lung Cancer 24: 17-24

Weynants P, Humblet Y, Jamart J (1997) Additional treatment does not improve the survival of locally advanced or metastatic NSCLC patients who responded after two courses of cisplatin, vindesin, mitomycin chemotherapy. Lung Cancer 18(Suppl): 48 